Article

\title{
Development of Mass Production Technology of Highly Permeable Nano-Porous Supports for Silica-Based Separation Membranes
}

\author{
Ken-ichi Sawamura * ${ }^{\mathbb{D}}$, Shigeru Okamoto and Yoshihiro Todokoro \\ eSep Inc., Keihanna Open Innovation Center @ Kyoto (KICK),1-5-7 Seikadai, Seika-cho, Souraku-gun, \\ Kyoto 619-0238, Japan \\ * Correspondence: sawamura@esep-membrane.com
}

Received: 2 July 2019; Accepted: 14 August 2019; Published: 16 August 2019

\begin{abstract}
Silica-based membranes show both robust properties and high-permeability, offering us great potential for applying them to harsh conditions where conventional organic membranes cannot work. Despite the increasing number of paper and patents of silica-based membranes, their industrial applications have yet to be fully realized, possibly due to their lack of technologies on scaling-up and mass production. In particular, quality of membrane supports decisively impacts final quality of silica-based separation membranes. In this study, therefore, we have developed mass producing technologies of nano-porous supports ( $\varphi 12 \mathrm{~mm}$, length $400 \mathrm{~mm}$ ) with surface center pore size distribution of 1-10 nm, which are generally used as supports for preparing separation membranes with a pore size of less than $1 \mathrm{~nm}$. The developed mass production apparatuses have enabled us to reproducibly produce nano-porous silica-based supports with high permeance (e.g., $\mathrm{N}_{2}$ permeance of more than $10^{-5} \mathrm{~mol} \mathrm{~m}^{-2} \mathrm{~s}^{-1} \cdot \mathrm{Pa}^{-1}$ ) minimizing effects of membrane defects less than $0.1 \%$ of the total flux. The developed nano-porous supports have enabled us to reproducibly produce silica-based separation membranes with high permeace and selectivity (e.g., $\mathrm{H}_{2}$ permeance of about $5 \times 10^{-6} \mathrm{~mol} \mathrm{~m}^{-2} \mathrm{~s}^{-1} \mathrm{~Pa}^{-1}$ and $\mathrm{H}_{2} / \mathrm{SF}_{6}$ permeance ratio of more than 2000 ).
\end{abstract}

Keywords: gas separation; pore size control; molecular sieve

\section{Introduction}

Membrane-based separation is one of the promising technologies for simplifying processes and reducing energy consumption drastically in future chemical and petroleum industries. Silica-based membranes, such as $\mathrm{SiO}_{2}$ membranes [1], $\mathrm{SiO}_{2}-\mathrm{ZrO}_{2}$ membranes [2], or organo-silica membranes [3-5], show both robust properties and high-permeability, offering us great potential for applying them to harsh conditions where conventional organic membranes cannot work.

Despite the increasing number of papers and patents of silica-based membranes, their industrial applications have yet to be fully realized, possibly due to lack of technologies on scaling-up and mass production. In particular, the quality of membrane supports decisively impacts final quality of silica-based separation membranes. Considering industrial applications and their economic feasibility of ceramic-based separation membranes, the permeance of target separation molecules are expected to be more than $10^{-6} \mathrm{~mol} \mathrm{~m} \mathrm{~m}^{-2} \mathrm{~s}^{-1} \mathrm{~Pa}^{-1}$ in most cases, such as hydrogen separation and water separation. Generally, silica-based molecular sieve separation layers with their pore size of less than $1 \mathrm{~nm}$ are formed on the surface or inside of nano-porous supports with a pore size of 1-10 nm. In order to obtain high-flux (more than $10^{-6} \mathrm{~mol} \mathrm{~m}^{-2} \mathrm{~s}^{-1} \mathrm{~Pa}^{-1}$ ) and high-selective membrane with their pore size of less than $1 \mathrm{~nm}$, the permeances of the nano-porous supports with their pore size distribution of 1-10 nm need to be more than $10^{-5} \mathrm{~mol} \mathrm{~m}^{-2} \mathrm{~s}^{-1} \mathrm{~Pa}^{-1}$. In addition, effects of permeation pathway 
through defects, such as pinholes or cracks of the nano-porous supports should be minimized to obtain reasonable separation performance after membrane separation layer coated.

The purpose of this study is to develop mass producing technologies of industrially applicable, highly permeable, and defect-free nano-porous supports for producing silica-based membranes. In this study, firstly, highly permeable silica-based nano-porous supports were developed by controlling size of nano-particles deposited on the surface of the supports. Secondly, an example of our mass-producing apparatus for the nano-porous supports was introduced. Finally, the developed nano-porous supports were tested to prepared silica-based separation membranes for hydrogen separation.

\section{Materials and Methods}

In order to effectively develop technologies on scaling-up and mass production of silica-based supports and membranes, we focused on clarifying correlations among synthesis conditions, structural properties, and gas permeation properties. Materials and methods of synthesis, structural characterization, and gas permeation tests are shown below.

\subsection{Synthesis}

Silica-based nano-porous supports and membranes were formed on $\alpha$-alumina symmetric porous tubes (average pore size: $3 \mu \mathrm{m}$, outside diameter $\phi: 12 \mathrm{~mm}$, length: $400 \mathrm{~mm}$, IWAO JIKI KYOGYO Co., Ltd., Saga prefecture, Japan) by sol-gel method, based on the procedure reported by the research group of Hiroshima University [1-5]. First, $\alpha$-alumina particles (average size: $0.2 \mu \mathrm{m}$ ) were coated on the $\alpha$-alumina porous support to obtain a smooth surface layer ( $\alpha$-alumina intermediate layer). Next, silica-based intermediate layers were formed on the surface of the $\alpha$-alumina intermediate layer, using colloidal sols of $\mathrm{SiO}_{2}$ [1], $\mathrm{SiO}_{2}-\mathrm{ZrO}_{2}(\mathrm{Si} / \mathrm{Zr}=1)$ [2], or 1,2-bis(triethoxysilyl)ethane (BTESE)-derived organo-silica [3-5]. The colloidal sols were prepared by hydrolysis and condensation reactions of tetra-ethoxysilene (TEOS), zirconium tetra n-butoxide, or BTESE. The detail preparation procedures of colloidal sols were reported elsewhere [1-5]. The particle sizes of the colloidal sols were controlled by adjusting sol concentration (1-2 wt \%), aging time (1-30 days), and aging temperature $\left(25-40{ }^{\circ} \mathrm{C}\right)$.

In this study, the hot coating method [1] was employed for quick formation of a thin active top layer on the substrate. Colloidal sols of $\mathrm{SiO}_{2}$ or $\mathrm{SiO}_{2}-\mathrm{ZrO}_{2}$ were coated on the $\alpha$-alumina intermediate layers at $180{ }^{\circ} \mathrm{C}$ and fired at $550{ }^{\circ} \mathrm{C}$ repeatedly for synthesizing silica-based nano-porous supports. BTESE-derived organo-silica membranes were synthesized based on the procedure reported by the research group of Hiroshima University [5]. Some experimental conditions were modified to improve productivity, as mentioned below. Colloidal sols of BTESE-derived organo-silica ( $0.5 \mathrm{wt} \%$ in ethanol) were coated on the $\mathrm{SiO}_{2}-\mathrm{ZrO}_{2}$ nano-porous supports at $145^{\circ} \mathrm{C}$ with a piece of wet cloth and fired at $350{ }^{\circ} \mathrm{C}$ for $7 \mathrm{~min}$ in $\mathrm{N}_{2}$ repeatedly for synthesizing gas separation membranes. This procedure was repeated 4 times to obtain BTESE membranes with less defects. The $\mathrm{SiO}_{2}-\mathrm{ZrO}_{2}$ nano-porous supports used for synthesizing the BTESE membranes had high permeance (e.g., $\mathrm{N}_{2}$ permeance of more than $10-5 \mathrm{~mol} \mathrm{~m}^{-2} \mathrm{~s}^{-1} \mathrm{~Pa}^{-1}$ ) with an average pore size of about $1-2 \mathrm{~nm}$, as shown later.

Figure 1 shows two types of experimental apparatuses (batch-type and flow-type) for synthesizing silica-based nano-porous supports and membranes. In this study, the batch-type apparatus was used for obtaining fundamental experimental data. In the batch-type apparatus, first, the substrates were preheated in a heating oven at 145 or $180^{\circ} \mathrm{C}$ for $4 \mathrm{~min}$. Next, each colloidal sol was coated on the surface of preheated substrates by contacting it with a piece of wet cloth. Then, the supports or membranes were directly inserted in a furnace at 350 or $550{ }^{\circ} \mathrm{C}$ and kept there for $7-15 \mathrm{~min}$. After the firing, the supports or membranes were naturally cooled for 4-10 $\mathrm{min}$. These procedures were manually repeated 4-10 times with each colloidal sol prepared. In case of the batch-type apparatus in Figure 1, average productivity of the hot coating of each colloidal sol was limited to 10 samples per unit furnace. 


\section{(A) Batch-type (manual operation)}

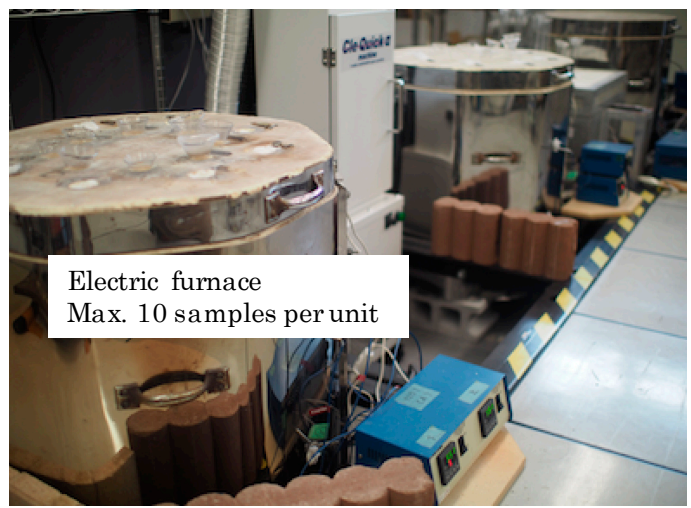

(B) Flow-type (automatic operation)

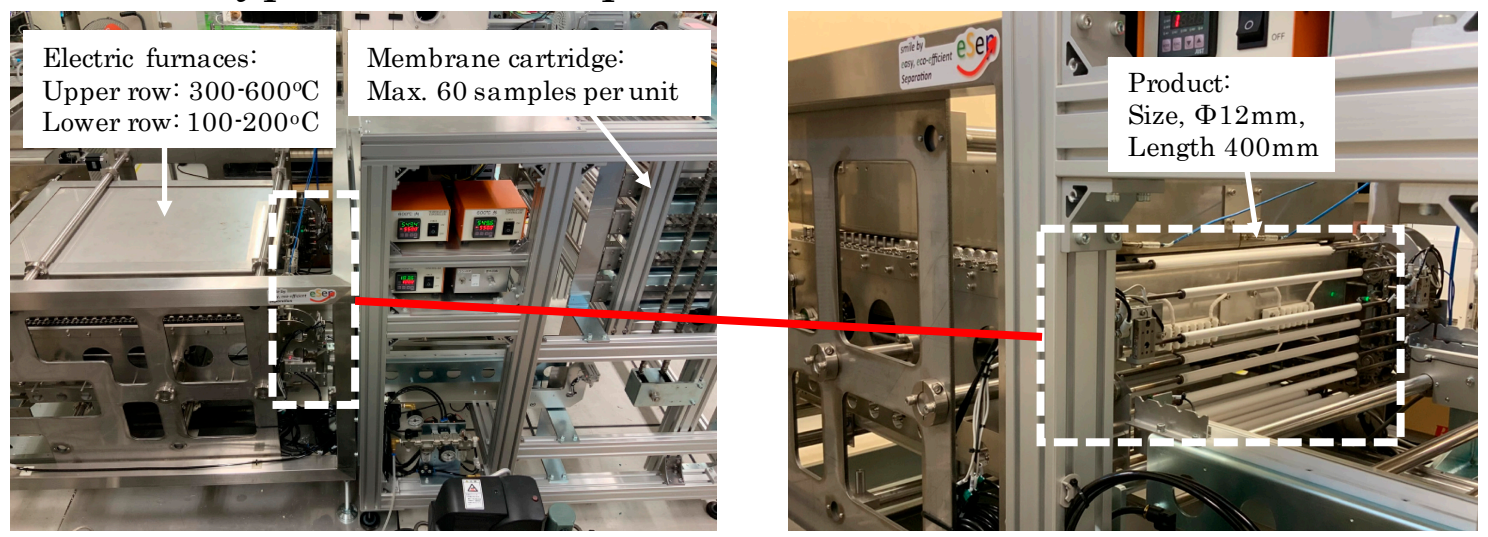

Figure 1. Experimental apparatuses for synthesizing silica-based nano-porous supports and membranes used in this study: (A) Batch-type and (B) flow-type apparatuses.

In order to enhance the productivity, a flow-type apparatus was prototyped. In the flow-type apparatus, substrates samples are designed to be circulated from preheating chamber at $180{ }^{\circ} \mathrm{C}$ for $10 \mathrm{~min} \rightarrow$ hot coating device $\rightarrow$ firing chamber at $550{ }^{\circ} \mathrm{C}$ for $10 \mathrm{~min} \rightarrow$ cooling chamber for 4-6 min. The residence times in each of the chambers were controlled by adjusting the feeding speed of belt conveyors. The flow-type apparatus has enabled the coating cycle to repeat continuously and automatically. Compared with the batch-type apparatus (manual operation), the flow-type apparatus (automatic operation) in Figure 1 improved the productivity from 10 to 60 samples per unit apparatus. For example, 6 times coating of 60 samples with one kind of colloidal sol will be completed within $3 \mathrm{~h}$ using the flow-type apparatus. In case of the flow-type apparatus, its production capacity will be easily expanded by increasing the number of membrane cartridge and prolong the line of electric furnaces.

\subsection{Structural Characterization}

The sizes of colloidal sols of $\mathrm{SiO}_{2}, \mathrm{SiO}_{2}-\mathrm{ZrO}_{2}$, and organo-silica synthesized were measured by a dynamic light scattering (DLS) analyzer (Malvern Zetasizer Nano ZS, Worcestershire, England) and a transmission electron microscope (TEM). The structures of synthesized silica-based nano-porous supports were observed by a scanning electron microscope (SEM).

\subsection{Gas Permeation Test}

Two types of gas permeation tests, a nano-permporometory [6,7] and single gas permeation tests, were employed to evaluate quality of synthesized silica-based nano-porous supports and membranes.

The synthesized silica-based nano-porous supports were evaluated by a nano-permporometory, which is suitable for investigating pore size distribution in the range of $1-10 \mathrm{~nm}$. The synthesized 
silica-based membranes were evaluated by single-gas permeation tests, which are suitable for investigating membranes with their pore size of less than $1 \mathrm{~nm}$.

In the gas permeation tests, as-made nano-porous supports or membranes (outside diameter $\phi$ : $12 \mathrm{~mm}$, length: $400 \mathrm{~mm}$ ) were placed inside the module cell and sealed with silicon caps at both ends. The effective membrane was $143 \mathrm{~cm}^{2}$.

\subsubsection{Nano-Permporometory}

The pore size distribution of synthesized silica-based nano-porous supports was evaluated by a nano-permporometory. In this method, non-condensable gas permeances through a porous sample are measured with increasing relative pressure of condensable vapor in a stepwise manner. The contributions of gas permeations via a specific size of pores are estimated by blocking their nanopores with a vapor condensate. The diameters of the pores blocked by the condensate as a function of vapor partial pressure are estimated using the well-known Kelvin Equation (1)

$$
\mathrm{D}_{\mathrm{K}}=-4 v \sigma \cos \theta / \mathrm{RT} \ln \left(\mathrm{P} / \mathrm{P}_{\mathrm{s}}\right)
$$

where $D_{K}, v, \sigma$, and $\theta$ are Kelvin diameter, molar volume, surface tension, and contact angle, respectively. In this study, $\mathrm{N}_{2}$ (non-condensable gas) and water (condensable vapor) were used, assuming $\cos \theta=1$ in calculation of Kelvin diameter of $\mathrm{SiO}_{2}$ and $\mathrm{SiO}_{2}-\mathrm{ZrO}_{2}$-based nano-porous supports because both supports were hydrophilic, probably due to immediate formations of $-\mathrm{OH}$ at surface of the supports. The nano-permporometry measurements were performed at $25^{\circ} \mathrm{C}$.

The schematic diagram of the nano-permporometry measurements and their experimental conditions are shown in Figure 2 and Table 1, respectively. Samples were attached in a glass module and sealed with silicon caps as shown in Figure 2.

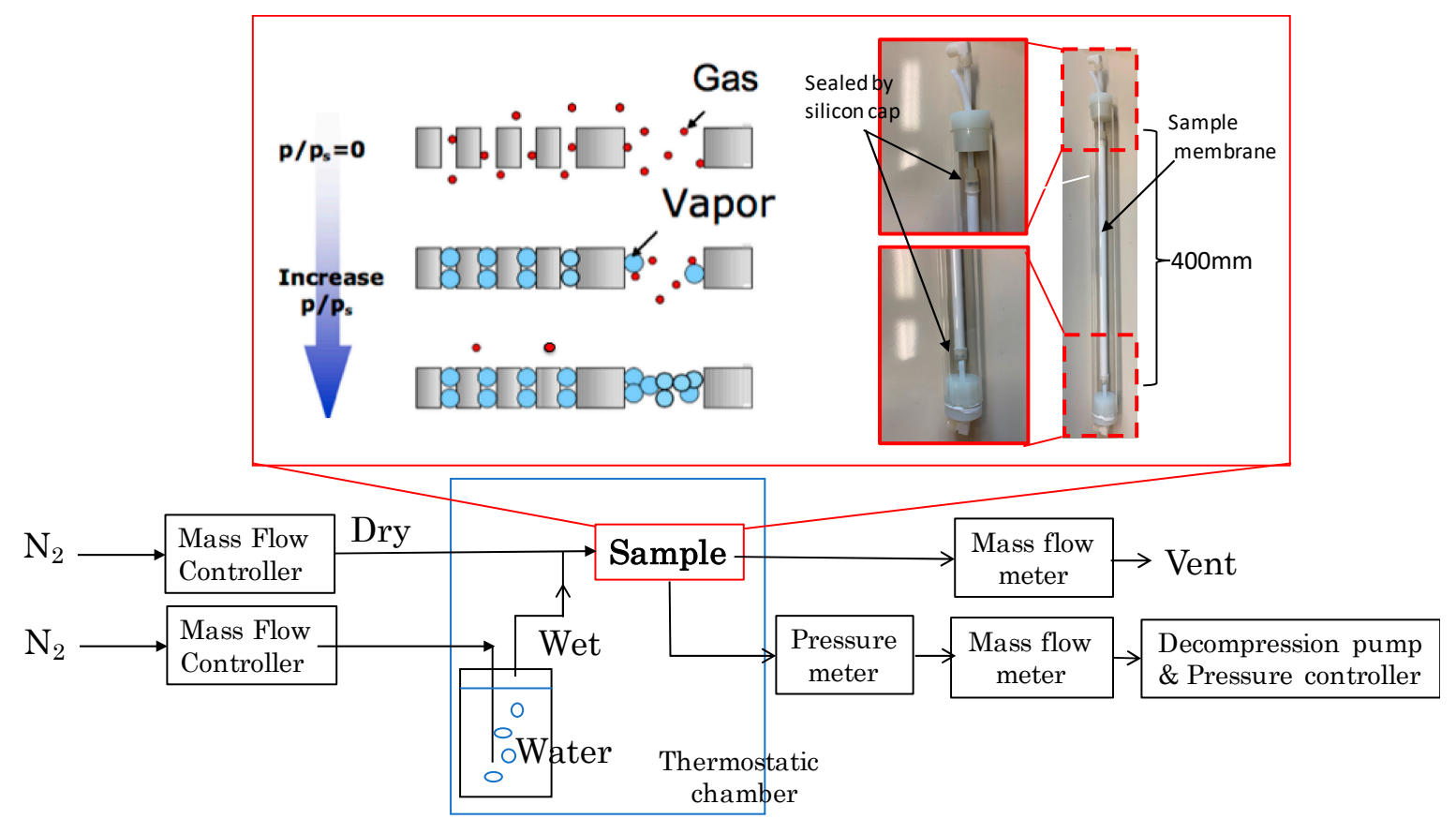

Figure 2. The schematic diagram of nano-permporometry measurements employed in this study. 
Table 1. Experimental conditions of nano-permporometry measurements in this study.

\begin{tabular}{ccccc}
\hline \multirow{2}{*}{ Step } & P/Ps [-] & Kenvin Diameter $[\mathbf{n m}]$ & \multicolumn{2}{c}{$\mathbf{N}_{\mathbf{2}}$ Flow $\left[\mathbf{L}(\mathbf{S T P}) \mathbf{~ m i n}^{\mathbf{- 1}}\right]$} \\
\cline { 4 - 5 } & & & $\mathbf{D r y}$ & Wet \\
\hline 1 & 0 & 0 & 5.00 & 0.00 \\
2 & 0.015 & 0.50 & 4.92 & 0.08 \\
3 & 0.062 & 0.75 & 4.69 & 0.31 \\
4 & 0.124 & 1.0 & 4.38 & 0.62 \\
5 & 0.248 & 1.5 & 3.76 & 1.24 \\
6 & 0.352 & 2.0 & 3.24 & 1.76 \\
7 & 0.498 & 3.0 & 2.51 & 2.49 \\
8 & 0.593 & 4.0 & 2.04 & 2.97 \\
9 & 0.658 & 5.0 & 1.71 & 3.29 \\
10 & 0.706 & 6.0 & 1.47 & 3.53 \\
11 & 0.742 & 7.0 & 1.29 & 3.71 \\
12 & 0.770 & 8.0 & 1.15 & 3.85 \\
13 & 0.793 & 9.0 & 1.04 & 3.97 \\
14 & 0.811 & 10.0 & 0.95 & 4.06 \\
\hline
\end{tabular}

\subsubsection{Single-Gas Permeation Test}

Single-gas permeation tests were conducted after membranes were preheated at $350{ }^{\circ} \mathrm{C}$ in $\mathrm{N}_{2}$ to remove chemisorbed water molecules. Samples were attached in a glass module and sealed with silicon caps. Pure gases of $\mathrm{H}_{2}(0.29 \mathrm{~nm}), \mathrm{CH}_{4}(0.38 \mathrm{~nm})$, or $\mathrm{SF}_{6}(0.55 \mathrm{~nm})$ were fed to the outside of a cylindrical membrane at $4-20 \mathrm{kPa}$. The gas permeation area was kept at $100{ }^{\circ} \mathrm{C}$ by a thermostatic chamber. The permeance of gases was measured by a bubble film meter.

\section{Results}

In this section, results of characterization of coating nano-particles, synthesized silica-based nano-porous supports, and membranes are shown in this order.

\subsection{Characterization of Coating Nano-Particles}

Table 2 summarizes estimated particle sizes of colloidal sols prepared with different synthesis conditions. The particle sizes of colloidal sols increased with increasing sol concentration, aging time, or aging temperature. TEM offers decisive evidence for determining the size of nano-particles when their clear images are obtained. Since relatively clear TEM images were obtained in Sample-1, Sample-2, Sample-4, and Sample-6, their TEM images are shown in Figure 3. Because clear TEM images of the other samples were not obtained in this study, their particle sizes are estimated by DLS. As shown in the Figure 3, the sizes of prepared nano-sol samples had some distributions.

Table 2. List of nano sol samples and their estimated particle sizes.

\begin{tabular}{|c|c|c|c|c|}
\hline Nano-Sol & Material & Preparation Conditions & Method & Estimaed Particle Size $[\mathrm{nm}]$ \\
\hline Sample-1 & $\mathrm{SiO}_{2}$ & $\begin{array}{l}2 \mathrm{wt} \% \text { in water, } \\
\text { aging at } 40{ }^{\circ} \mathrm{C} \text { for } 30 \text { day }\end{array}$ & DLS, TEM & $10-25$ \\
\hline Sample-2 & $\mathrm{SiO}_{2}$ & $\begin{array}{l}1 \mathrm{wt} \% \text { in water, } \\
\text { aging at } 40{ }^{\circ} \mathrm{C} \text { for } 30 \text { day }\end{array}$ & DLS, TEM & $5-15$ \\
\hline Sample-3 & $\mathrm{SiO}_{2}$ & $\begin{array}{c}1 \mathrm{wt} \% \text { in water, } \\
\text { aging at } 25^{\circ} \mathrm{C} \text { for } 30 \text { day }\end{array}$ & DLS & $3-10$ \\
\hline Sample-4 & $\mathrm{SiO}_{2}$ & $\begin{array}{c}0.5 \mathrm{wt} \% \text { in water, } \\
\text { aging at } 25{ }^{\circ} \mathrm{C} \text { for } 7 \text { day }\end{array}$ & DLS, TEM & $2-10$ \\
\hline Sample-5 & $\mathrm{SiO}_{2}-\mathrm{ZrO}_{2}$ & $\begin{array}{l}1 \mathrm{wt} \% \text { in water, } \\
\text { agin at } 25{ }^{\circ} \mathrm{C} \text { for } 7 \text { day }\end{array}$ & DLS & $2-10$ \\
\hline Sample-6 & $\mathrm{SiO}_{2}-\mathrm{ZrO}_{2}$ & $\begin{array}{c}0.5 \mathrm{wt} \% \text { in water, } \\
\text { aging at } 25^{\circ} \mathrm{C} \text { for } 7 \text { day }\end{array}$ & DLS, TEM & $2-5$ \\
\hline Sample-7 & $\begin{array}{l}\text { Organo-silica } \\
\text { (BTESE) }\end{array}$ & $\begin{array}{l}0.5 \mathrm{wt} \% \text { in ethanol, } \\
\text { aging at } 25^{\circ} \mathrm{C} \text { for } 1 \text { day }\end{array}$ & DLS & $1-2$ \\
\hline
\end{tabular}



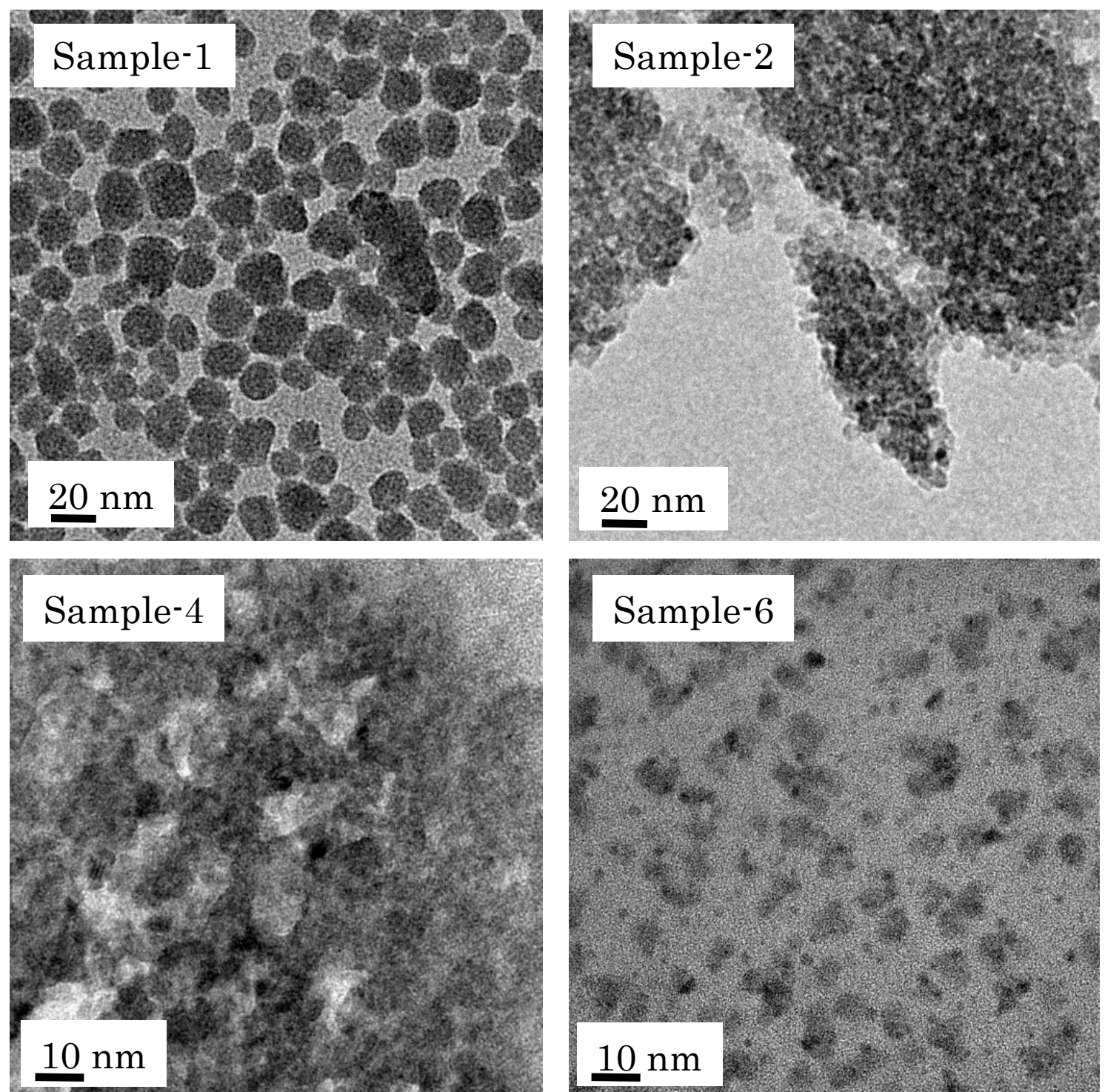

Figure 3. TEM images of nano-sol samples prepared in this study.

\subsection{Characterization of Synthesized Silica-Based Nano-Porous Supports}

In this section, characterization results of nano-porous supports and membranes synthesized using the batch-type apparatus (as shown in Figure 1) are explained except otherwise mentioned. The results of those synthesized using the flow-type apparatus are explained in Section 3.2.3.

\subsubsection{General Structure}

Figure 4 shows typical SEM images of the synthesized silica-based nano-porous supports. From the SEM images, three layers, attributed to the $\alpha$-alumina porous support layer, the $\alpha$-alumina intermediate layer, and the silica-base layer, were observed. The $\alpha$-alumina porous support layer was formed with large (more than $1 \mu \mathrm{m}$ ) alumina particles. The $\alpha$-alumina intermediate layer was formed with fine (about $0.2 \mu \mathrm{m}$ ) alumina particles on the upper surface of the $\alpha$-alumina porous support. The silica-based layers were formed on the upper surface of the $\alpha$-alumina intermediate layer. The total thickness of the silica-based layers was less than $500 \mathrm{~nm}$. The observed silica-based layer in Figure 4 was synthesized by multi-coating $\mathrm{SiO}_{2}$-based nano-sols of Sample-2 (5-15 nm) and Sample-4 (2-10 nm) in this order. Probably due to the limitation of resolution of the SEM, no clear boundary between the silica layers with different particle sizes were observed from the SEM observation. 

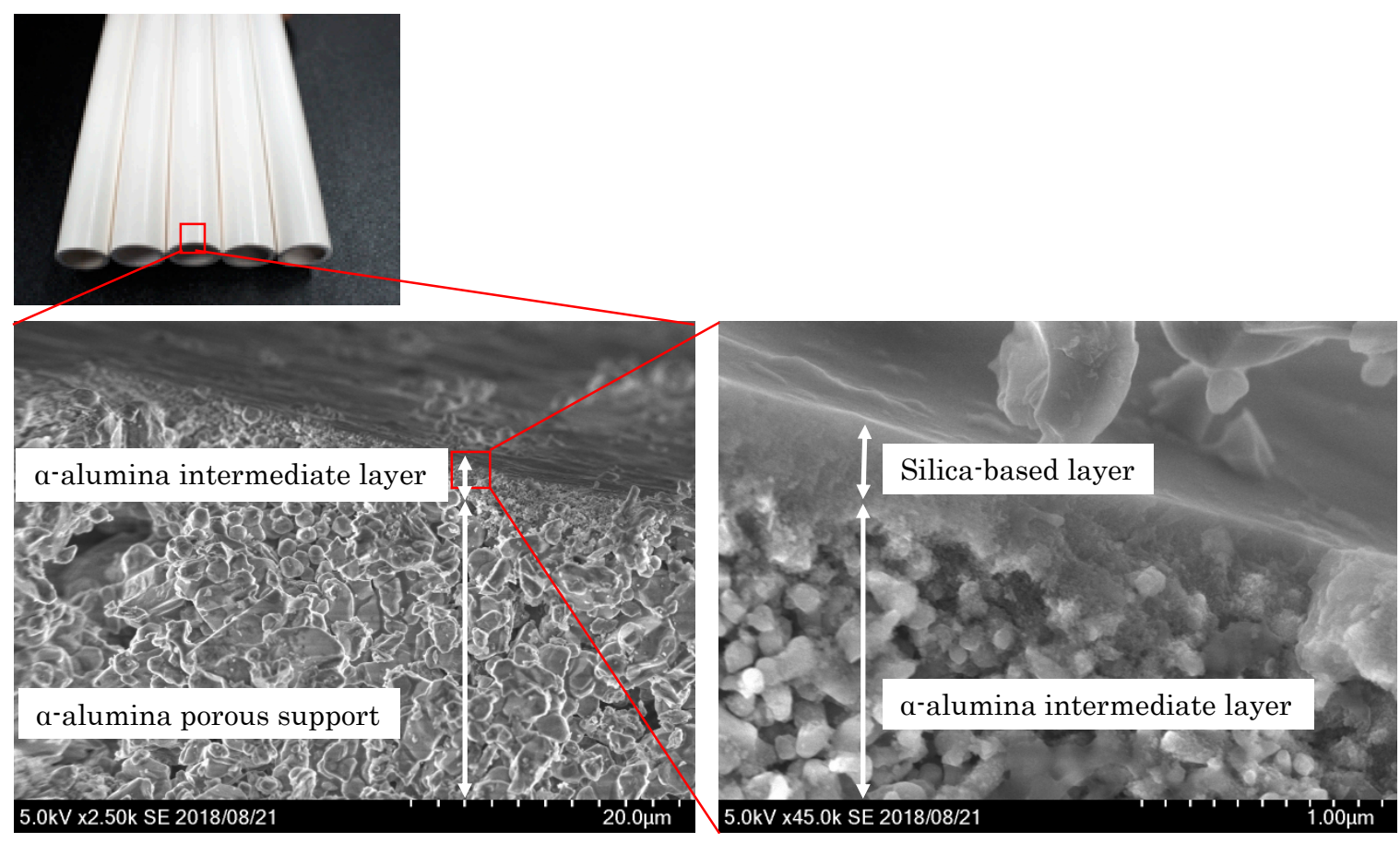

Figure 4. Typical SEM images of the synthesized nano-porous silica-based supports.

\subsubsection{Pore Size Distribution of $\mathrm{SiO}_{2}$-Based Nano-Porous Supports}

Nano-permporometry profiles of nano-porous supports prepared by coating nano-sol samples with different particle sizes are shown in Figure $5\left(\mathrm{SiO}_{2}\right.$-based nano-porous supports). Based on the results of nano-permporometry measurements, distributions of gas permeation ratio through each of permeation path with different pore sizes were calculated and summarized in Table 3.
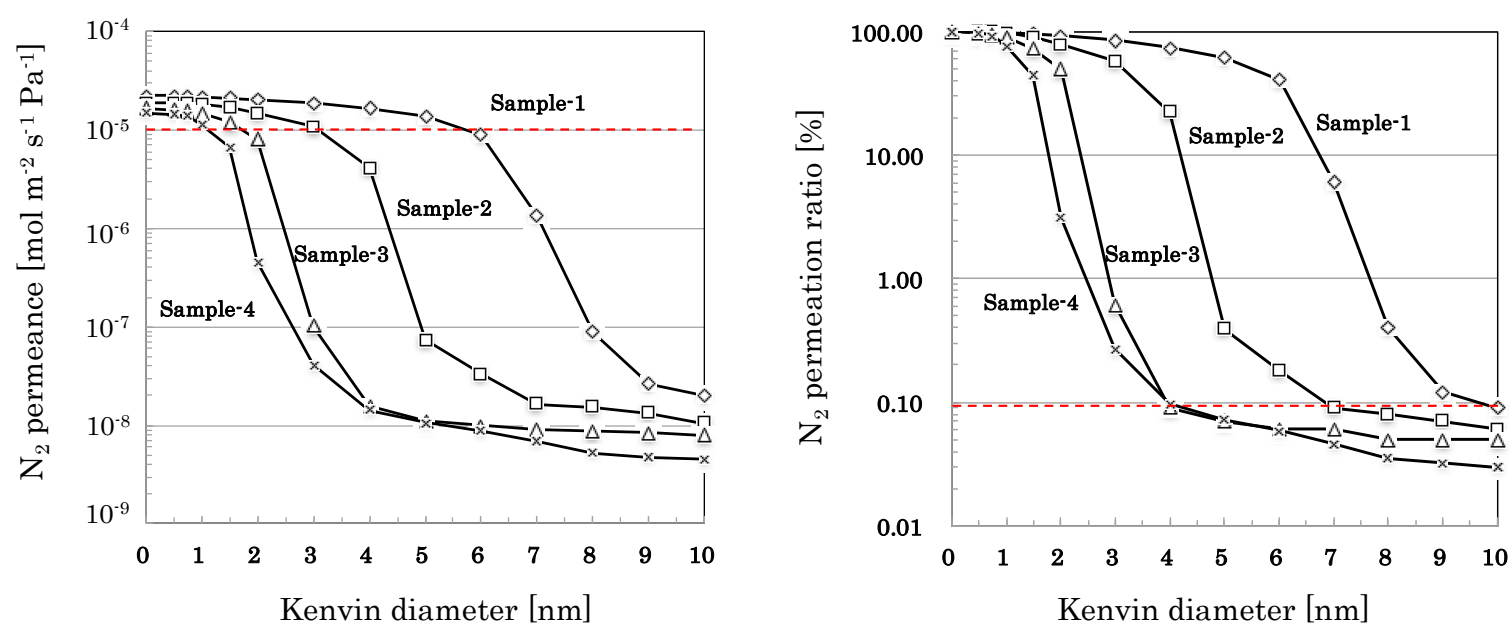

Figure 5. Nano-permporometry profiles of nano-porous supports prepared by coating $\mathrm{SiO}_{2}$-based nano-sol samples with different particle sizes. Sample-1, 2, and 3 were prepared by directly coating each of their nano-sol on the $\alpha$-alumina intermediate layer. Sample- 4 was prepared by coating the nano-sol of Sample- 4 on the surface of the nano-porous support of Sample-2. 
Table 3. Pore size distribution of $\mathrm{SiO}_{2}$-based nano-porous supports synthesized using different nano-sols.

\begin{tabular}{ccccc}
\hline \multirow{2}{*}{$\begin{array}{c}\text { Permeation Path } \\
\mathbf{r}[\mathbf{n m}]\end{array}$} & \multicolumn{4}{c}{ Permeation Ratio [\%] } \\
\cline { 2 - 5 } & Sample-1 & Sample-2 & Sample-3 & Sample-4 \\
\hline $0<\mathrm{r} \leq 1$ & 2.9 & 3.0 & 10.6 & 23.9 \\
$1<\mathrm{r} \leq 2$ & 5.4 & 18.3 & 40.1 & 73.0 \\
$2<\mathrm{r} \leq 3$ & 7.2 & 20.8 & 48.7 & 2.8 \\
$3<\mathrm{r} \leq 4$ & 10.1 & 35.7 & 0.53 & 0.17 \\
$4<\mathrm{r} \leq 5$ & 13.0 & 21.7 & 0.02 & 0.02 \\
$5<\mathrm{r} \leq 6$ & 20.9 & 0.21 & 0.01 & 0.01 \\
$6<\mathrm{r} \leq 7$ & 34.5 & 0.09 & 0.00 & 0.01 \\
$7<\mathrm{r} \leq 8$ & 5.72 & 0.01 & 0.01 & 0.01 \\
$8<\mathrm{r} \leq 9$ & 0.28 & 0.01 & 0.00 & 0.00 \\
$9<\mathrm{r} \leq 10$ & 0.03 & 0.01 & 0.00 & 0.00 \\
$10<\mathrm{r}$ & 0.09 & 0.06 & 0.05 & 0.03 \\
\hline
\end{tabular}

3.2.3. Reproducibility in the Flow-Type Production

Different from the manually operative batch-type apparatus, the automatic operative flow-type apparatus seems suitable for mass production of the nano-porous supports and membranes. Figure 6 and Table 4 compare nano-permporometry profiles of nano-porous supports prepared with the flow-type apparatus prototyped in this study. The nano-sol of Sample-3 was used to prepare the nano-porous supports with the prototyped apparatus. All samples measured seem to have almost the same nano-porometry profiles with high permeance (e.g., $\mathrm{N}_{2}$ permeance of more than $10^{-5} \mathrm{~mol} \mathrm{~m}^{-2} \mathrm{~s}^{-1} \mathrm{~Pa}^{-1}$ ) minimizing effects of membrane defects less than $0.1 \%$ of total flux.
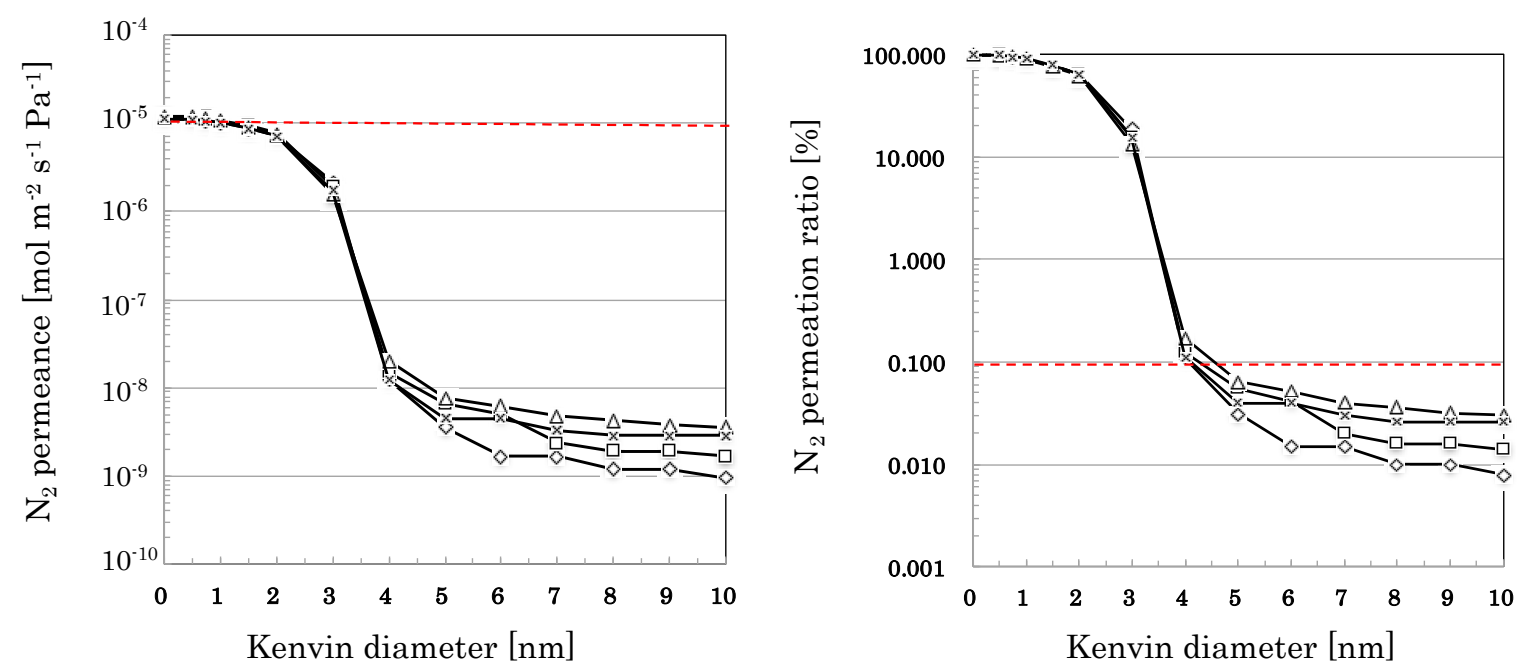

Figure 6. Nano-permporometry profiles of $\mathrm{SiO}_{2}$-based nano-porous supports prepared by coating the nano-sol of Sample-3 with the flow-type apparatus. 
Table 4. Pore size distribution of $\mathrm{SiO}_{2}$-based nano-porous supports prepared by coating the nano-sol of Sample-3 with the flow-type apparatus.

\begin{tabular}{ccccc}
\hline \multirow{2}{*}{$\begin{array}{c}\text { Permeation Path } \\
\mathbf{r}[\mathbf{n m}]\end{array}$} & $\begin{array}{c}\text { Sample-3 } \\
\mathbf{( F 1 )}\end{array}$ & $\begin{array}{c}\text { Sample-3 } \\
\mathbf{( F 2 )}\end{array}$ & $\begin{array}{c}\text { Sample-3 } \\
\mathbf{( F 3 )}\end{array}$ & $\begin{array}{c}\text { Sample-3 } \\
\mathbf{( F 4 )}\end{array}$ \\
\cline { 2 - 5 } & 10.5 & 10.5 & 9.3 & 8.5 \\
$0<\mathrm{r} \leq 1$ & 25.9 & 25.4 & 28.7 & 27.7 \\
$1<\mathrm{r} \leq 2$ & 44.7 & 48.4 & 48.7 & 48.2 \\
$2<\mathrm{r} \leq 3$ & 18.8 & 15.6 & 13.2 & 15.5 \\
$3<\mathrm{r} \leq 4$ & 0.08 & 0.07 & 0.11 & 0.07 \\
$4<\mathrm{r} \leq 5$ & 0.02 & 0.01 & 0.01 & 0.00 \\
$5<\mathrm{r} \leq 6$ & 0.00 & 0.02 & 0.01 & 0.01 \\
$6<\mathrm{r} \leq 7$ & 0.01 & 0.00 & 0.00 & 0.00 \\
$7<\mathrm{r} \leq 8$ & 0.00 & 0.00 & 0.00 & 0.00 \\
$8<\mathrm{r} \leq 9$ & 0.00 & 0.00 & 0.00 & 0.00 \\
$9<\mathrm{r} \leq 10$ & 0.01 & 0.01 & 0.03 & 0.03 \\
$10<\mathrm{r}$ & & & &
\end{tabular}

\subsubsection{Pore Size Distribution of $\mathrm{SiO}_{2}-\mathrm{ZrO}_{2}$-Based Nano-Porous Supports}

Compared with pure $\mathrm{SiO}_{2}$-based nano-porous supports, $\mathrm{SiO}_{2}-\mathrm{ZrO}_{2}$-based nano-porous supports are less stable in a strong acidic condition but more stable against water and alkali. Therefore, development of $\mathrm{SiO}_{2}-\mathrm{ZrO}_{2}$-based nano-porous supports are also indispensable for applying them to conditions where pure $\mathrm{SiO}_{2}$-based materials are unsuitable. $\mathrm{SiO}_{2}-\mathrm{ZrO}_{2}$-based nano-porous supports are often used as intermediate layers for preparing organo-silica membranes for gas separation [5], probably due to better stability against water.

Figure 7 shows nano-permporometry profiles of $\mathrm{SiO}_{2}-\mathrm{ZrO}_{2}$-based nano-porous supports prepared by coating nano-sol samples with different particle sizes Based on the results of nano-permporometry measurements, distributions of gas permeation ratio through each of permeation paths with different pore sizes were calculated and summarized in Table 5.
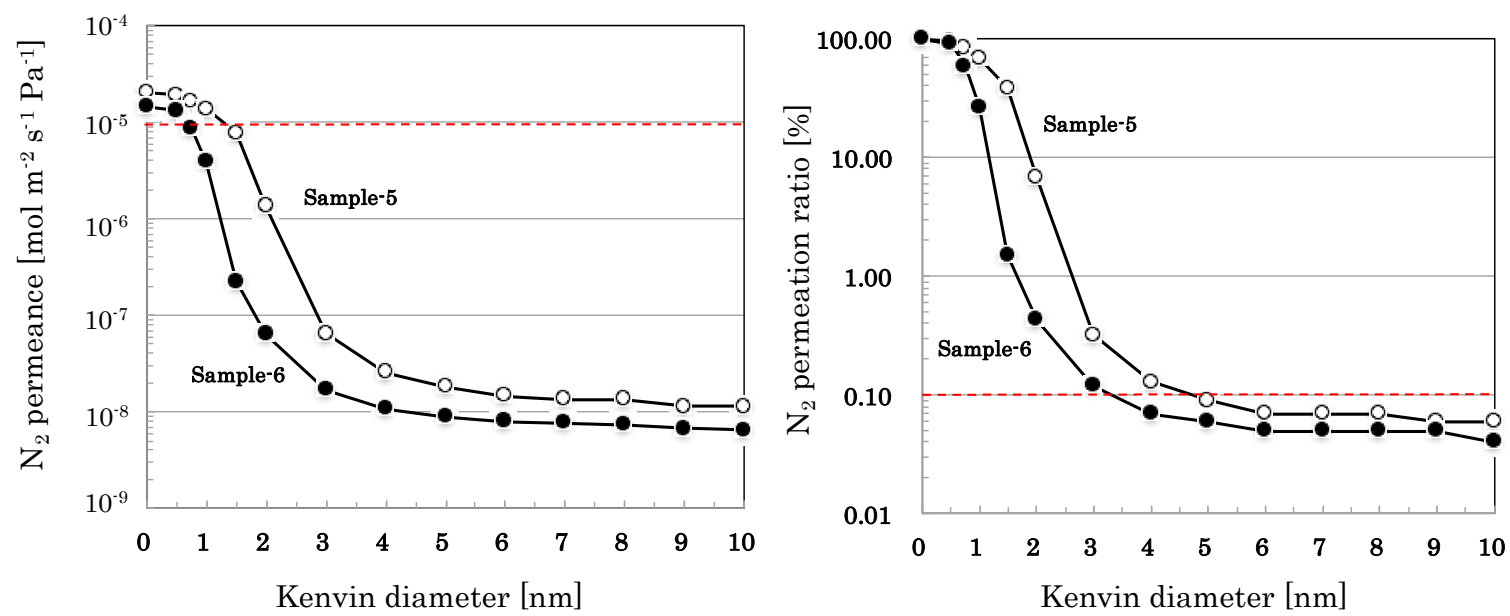

Figure 7. Nano-permporometry profiles of nano-porous supports prepared by coating $\mathrm{SiO}_{2}-\mathrm{ZrO}_{2}$-based nano-sol samples with different particle sizes. Sample- 5 was prepared by directly coating the nano-sol Sample- 5 on the $\alpha$-alumina intermediate layer. Sample- 6 was prepared by coating the nano-sol of Sample- 6 on the surface of the nano-porous support of Sample-5. 
Table 5. Pore size distribution of $\mathrm{SiO}_{2}-\mathrm{ZrO}_{2}$-based nano-porous supports synthesized using different nano-sols.

\begin{tabular}{ccc}
\hline Permeation Path & \multicolumn{2}{c}{ Permeation Ratio [\%] } \\
\cline { 2 - 3 } $\mathbf{r}[\mathbf{n m}]$ & Sample-5 & Sample-6 \\
\hline $0<\mathrm{r} \leq 1$ & 31.8 & 73.4 \\
$1<\mathrm{r} \leq 2$ & 61.5 & 26.2 \\
$2<\mathrm{r} \leq 3$ & 6.4 & 0.31 \\
$3<\mathrm{r} \leq 4$ & 0.19 & 0.05 \\
$4<\mathrm{r} \leq 5$ & 0.04 & 0.01 \\
$5<\mathrm{r} \leq 6$ & 0.02 & 0.01 \\
$6<\mathrm{r} \leq 7$ & 0.00 & 0.00 \\
$7<\mathrm{r} \leq 8$ & 0.00 & 0.00 \\
$8<\mathrm{r} \leq 9$ & 0.01 & 0.00 \\
$9<\mathrm{r} \leq 10$ & 0.00 & 0.01 \\
$10<\mathrm{r}$ & 0.06 & 0.04 \\
\hline
\end{tabular}

\subsection{Characterization of Synthesized Organo-Silica Membranes}

The BTESE-derived organo-silica membranes were synthesized by multi-coatings of nano-sols of Sample-5 ( $\left.\mathrm{SiO}_{2}-\mathrm{ZrO}_{2}, 2-10 \mathrm{~nm}\right)$, Sample-6 $\left(\mathrm{SiO}_{2}-\mathrm{ZrO}_{2}, 2-5 \mathrm{~nm}\right)$, and Sample-7 (BTESE derived organo-silica, $1.5 \mathrm{~nm}$ ) in this order. Different from the other samples (Sample 1 to 6), Sample-7 (BTESE derived organo-silica) showed water-repellent property. Since the top surface of the organo-silica membranes seem hydrobobic with their pore size of less than $1 \mathrm{~nm}$, single-gas permeation tests through the membranes were employed. The results of single-gas permeation tests are listed in Table 6.

Table 6. Gas permeation properties of membranes synthesized using the nano-porous supports of Sample-6 and nano-sol of Sample-7.

\begin{tabular}{|c|c|c|c|}
\hline \multirow{2}{*}{ Membrane } & \multirow{2}{*}{$\begin{array}{l}\mathrm{H}_{2} \text { Permeance } 10^{-6} \\
{\left[\mathrm{~mol} \mathrm{~m}^{-2} \mathrm{~s}^{-1} \mathrm{~Pa}^{-1}\right]}\end{array}$} & \multicolumn{2}{|c|}{ Ratio of Permeance [ - ] } \\
\hline & & $\mathrm{H}_{2} / \mathrm{CH}_{4}$ & $\mathrm{H}_{2} / \mathrm{SF}_{6}$ \\
\hline Membrane 1 & 5.21 & 10.6 & $>2000$ \\
\hline Membrane 2 & 4.85 & 19.7 & $>2000$ \\
\hline Membrane 3 & 4.05 & 23.7 & $>2000$ \\
\hline Membrane 4 & 5.60 & 14.0 & $>2000$ \\
\hline Membrane 5 & 4.44 & 21.4 & $>2000$ \\
\hline Membrane 6 & 5.56 & 8.2 & 273 \\
\hline
\end{tabular}

\section{Discussion}

\subsection{Correlations Among Synthesis Conditions, Structural Properties, and Gas Permeation Properties}

Generally, coating nano-particle's sizes and their distributions critically influence on pore size distribution of the prepared nano-porous supports. Nano-sols with uniform size of nano-particles seem best for preparing a nano-porous support with a specific pore size. In reality, however, the sizes of nano-particles of prepared nano-sols had distributions to some extent, as shown in Table 2. In case of spherical particles with uniform size, pore size of their close packing should be $1 / 3$ of the spherical particles. As shown in Tables 3-5, pore size distributions of nano-porous supports synthesized showed relatively good correlations with the sizes of nano-particles used. Nano-porous supports with more uniform pore distribution will be synthesized with more uniform size of nano-particles in near future.

\subsection{Quality of Nano-Porous Supports and Membranes}

High-quality nano-porous supports and/or membranes should be highly-permeable with specific pore size distributions. Generally, thinner layers show higher permeability; however, thinner layers are more difficult to form defect-free. Existence of defects, such as pinholes and/or cracks form large pores, 
deteriorates their intended pore size distributions. From the SEM observations as shown in Figure 4, the silica-based layer prepared seems thin (less than $500 \mathrm{~nm}$ ) with no clear defects. Since no clear (more than $100 \mathrm{~nm}$ ) increase of layer's thickness was observed after coating smaller nano-particles (Sample-4, 6, and 7) on nano-porous supports of Sample-2 and 5, effective thickness of the silica-based layer composed of smaller nano-particles (Sample-4, 6, and 7) would be less than $100 \mathrm{~nm}$.

The developed nano-porous silica-based supports showed high permeance (e.g., $\mathrm{N}_{2}$ permeance of more than $10^{-5} \mathrm{~mol} \mathrm{~m}^{-2} \mathrm{~s}^{-1} \mathrm{~Pa}^{-1}$ ), minimizing effects of large pores (e.g., more than $10 \mathrm{~nm}$ ) less than $0.1 \%$ of total flux, as shown in Figures 5-7. Using the developed nano-porous silica-based supports, organo-silica membranes high permeace and selectivity (e.g., $\mathrm{H}_{2}$ permeance of about $5 \times 10^{-6} \mathrm{~mol}$ $\mathrm{m}^{-2} \mathrm{~s}^{-1} \mathrm{~Pa}^{-1}$ and $\mathrm{H}_{2} / \mathrm{SF}_{6}$ permeance ratio of more than 2000) were reproducibly produce, as shown in Table 6. The membranes showed small permeation of $\mathrm{CH}_{4}(0.38 \mathrm{~nm})$ and little permeation of $\mathrm{SF}_{6}$, the effective pore sizes of the membranes were estimated to be $0.4-0.5 \mathrm{~nm}$. Since the type of organo-silica sol employed in this study was BTESE, the network structure of BTESE(-Si-C-C-Si-) would allow permeation of smaller molecules, or $\mathrm{H}_{2}(0.29 \mathrm{~nm}), \mathrm{N}_{2}(0.36 \mathrm{~nm})$, and $\mathrm{CH}_{4}(0.38 \mathrm{~nm})$, and block permeation of larger molecules, $\mathrm{SF}_{6}(0.55 \mathrm{~nm})$ [8]. Judging from the $\mathrm{H}_{2}$ permselectivity for silica-based membranes and zeolite membranes, Kanezashi et al. [5] estimated the order of average pore size as follows: TEOS-derived silica membrane [9] (up to $0.3 \mathrm{~nm}$ ) < DDR-type zeolite membrane [10] (up to $0.45 \mathrm{~nm}$ ) < BTESE-derived silica membrane [5] (up to $0.5 \mathrm{~nm}$ ) < MFI-type zeolite membrane [11] (up to $0.56 \mathrm{~nm}$ ). Therefore, BTESE-derived silica membranes are expected to apply to separation of hydrogen/organic gas mixtures such as hydrogen/propane, hydrogen/isobutene, and hydrogen/toluene.

The $\mathrm{H}_{2}$ permeation properties of the obtained BTESE-derived silica membranes were compared with those reported by other groups in Table 7. The permselectivity of BTESE-derived silica membranes were almost the same; however, $\mathrm{H}_{2}$ permeances were largely different from each other. In general, BTESE-derived silica membranes with their intermediate layer of $\mathrm{SiO}_{2}-\mathrm{ZrO}_{2}$ showed higher $\mathrm{H}_{2}$ permeance than those with their intermediate layer of $\gamma$-alumina [12-14], probably due to the higher permeability of $\mathrm{SiO}_{2}-\mathrm{ZrO}_{2}$ intermediate layer than those of $\gamma$-alumina intermediate layer. The research group of Hiroshima University used $\mathrm{SiO}_{2}-\mathrm{ZrO}_{2}$ intermediate layers and reported high $\mathrm{H}_{2}$ permeance of BTESE-derived silica membranes $[5,15,16]$; however, their $\mathrm{H}_{2}$ permeances differed by one order of magnitude. We assume the variation of $\mathrm{H}_{2}$ permeation is probably due to the difference in the permeability of intermediate layers synthesized.

We assume the use of highly permeable nano-porous supports greatly contributed to the high $\mathrm{H}_{2}$ permeanes of organo-silica (BTESE) membranes synthesized. Compared with $\gamma$-alumina intermediate layered supports [12,13], the permeability of the $\mathrm{SiO}_{2}-\mathrm{ZrO}_{2}$ intermediate layered supports developed in this study were more than ten times higher, resulting in more than ten times higher $\mathrm{H}_{2}$ permeances of BTESE-derived silica membranes. In this study, we have succeeded in scaling-up the high quality BTESE-derived organo-silica membranes reported by the research group of Hiroshima University [5] from the lab size ( $\varphi 10 \mathrm{~mm}$, length up to $100 \mathrm{~mm}$, employed in the research group of Hiroshima University) to an industrial size ( $\varphi 12 \mathrm{~mm}$, length $400 \mathrm{~mm}$ ). 
Table 7. $\mathrm{H}_{2}$ permeation properties of 1,2-bis(triethoxysilyl)ethane (BTESE)-derived silica membranes.

\begin{tabular}{|c|c|c|c|c|c|c|c|c|}
\hline \multicolumn{3}{|c|}{ Intermediate Layer } & \multicolumn{5}{|c|}{ After BTESE-Derived Silica Coated } & \multirow{3}{*}{ Reference } \\
\hline \multirow{2}{*}{ Material } & \multirow{2}{*}{$\begin{array}{c}\mathrm{N}_{2} \text { Permeance } \\
{\left[10^{-6} \mathrm{~mol} \mathrm{~m}^{-2} \mathrm{~s}^{-1} \mathrm{~Pa}^{-1}\right]}\end{array}$} & \multirow{2}{*}{$\begin{array}{l}\text { Average Pore } \\
\text { Size }[\mathrm{nm}]\end{array}$} & \multirow{2}{*}{$\begin{array}{c}\mathrm{H}_{2} \text { Permeance } \\
{\left[10^{-6} \mathrm{~mol} \mathrm{~m}^{-2} \mathrm{~s}^{-1} \mathrm{~Pa}^{-1}\right]}\end{array}$} & \multicolumn{3}{|c|}{ Selectivity } & \multirow{2}{*}{$\begin{array}{c}\text { Measurement } \\
\text { Temperature }\left[{ }^{\circ} \mathrm{C}\right]\end{array}$} & \\
\hline & & & & $\mathrm{H}_{2} / \mathrm{N}_{2}$ & $\mathrm{H}_{2} / \mathrm{CH}_{4}$ & $\mathrm{H}_{2} / \mathrm{SF}_{6}$ & & \\
\hline$\gamma$-alumina & $0.1-1$ & $1.7-5$ & $0.2-0.5$ & $7-20$ & $7-20$ & - & 200 & ten Hove et al. [12,13] \\
\hline$\gamma$-alumina & - & 4 & 0.25 & $20-30$ & - & - & 200 & Agirre et al. [14] \\
\hline $\mathrm{SiO}_{2}-\mathrm{ZrO}_{2}$ & 4 & 0.65 & 1 & up to 100 & - & - & 200 & Nagasawa et al. [15] \\
\hline $\mathrm{SiO}_{2}-\mathrm{ZrO}_{2}$ & - & several & $1-4$ & $10-100$ & - & $100-10,000$ & $100-200$ & Yu et al. [16] \\
\hline $\mathrm{SiO}_{2}-\mathrm{ZrO}_{2}$ & - & several & $2-10$ & $9-23$ & - & $1000-25,500$ & $100-300$ & Kanezashi et al. [5] \\
\hline $\mathrm{SiO}_{2}-\mathrm{ZrO}_{2}$ & 15 & 0.8 & $4.4-5.6$ & - & $10-23$ & $>2000$ & 100 & This work \\
\hline
\end{tabular}




\subsection{Mass Producibility}

Considering mass production of silica-based membranes, both sol-gel methods [1-5] and chemical vapor deposition (CVD) methods [17] would be candidates; however, sol-gel methods seem more cost-effective in preparing nano-porous supports because silica-based intermediate layers with controlled pore size distributions can be formed immediately by just coating and heating nano-particles with a specific size in order. As shown in Figure 6 and Table 4, silica-based nano-porous supports were reproducibly obtained by using the flow-type apparatus shown in Figure 1. In the flow-type production, operations in a typical sol-gel method, or the cycle of preheating $\rightarrow$ hot coating of nano-particles $\rightarrow$ firing, can be performed continuously and automatically. In this study, we have confirmed that mass productions of silica-based nano-porous supports were principally possible by the flow-type sol-gel method. Actual mass production of silica-based nano-porous supports and membranes will be our next research.

\section{Conclusions}

In this study, we have successfully scaled-up high quality silica-based nano-porous supports and membranes by controlling sizes of nano-particles coated. The developed nano-porous silica-based supports have showed high permeance (e.g., $\mathrm{N}_{2}$ permeance of more than $10^{-5} \mathrm{~mol} \mathrm{~m}^{-2} \mathrm{~s}^{-1} \mathrm{~Pa}^{-1}$ ), minimizing effects of membrane defects less than $0.1 \%$ of total flux. The developed nano-porous supports have enabled us to reproducibly produce silica-based separation membranes with high permeance and selectivity (e.g., $\mathrm{H}_{2}$ permeance of about $5 \times 10^{-6} \mathrm{~mol} \mathrm{~m}^{-2} \mathrm{~s}^{-1} \mathrm{~Pa}^{-1}$ and $\mathrm{H}_{2} / \mathrm{SF}_{6}$ permeance ratio of more than 2000). In additions, a flow-type sol-gel method was developed for the mass productions of silica-based nano-porous supports and membranes.

Author Contributions: Conceptualization, K.-i.S.; methodology, K.-i.S., Y.T; validation, K.-i.S., Y.T.; formal analysis, K.-i.S., S.O, and Y.T.; investigation, K.-i.S., S.O, and Y.T.; writing-original draft preparation, K.-i.S.; writing-review and editing, K.-i.S.; visualization, K.-i.S.; supervision, K.-i.S.; project administration, K.-i.S.; funding acquisition, K.-i.S.

Funding: Part of this research was funded by the New Energy and Industrial Technology Development Organization (NEDO) and Public Interest Incorporated Foundation KYOTO Industrial Support Organization 21.

Acknowledgments: SEM and TEM observations were supported by “NAIST Nanotechnology Platform” operated by the Ministry of Education, Culture, Sports, Science and Technology (MEXT), Japan.

Conflicts of Interest: The authors declare no conflict of interest.

\section{References}

1. Asaeda, M.; Ishida, M.; Waki, T. Pervaporation of Aqueous Organic Acid Solutions by Porous Ceramic Membranes. J. Chem. Eng. Jpn. 2005, 38, 336-343. [CrossRef]

2. Asaeda, M.; Yang, J.; Sakou, Y. Porous silica-zirconia (Zr, 50\%) membranes for oervaporation of iso-propyl alcohol (IPA)/water mixtures. J. Chem. Eng. Jpn. 2002, 35, 365-371. [CrossRef]

3. Tsuru, T.; Shibata, T.; Wang, J.; Lee, H.R.; Kanezashi, M.; Yoshioka, T. Pervaporation of Acetic Acid Aqueous Solutions by Organosilica Membranes. J. Membr. Sci. 2012, 421-422, 25-31. [CrossRef]

4. Kanezashi, M.; Yada, K.; Yoshioka, T.; Tsuru, T. Design of silica networks for development of highly permeable hydrogen separation membranes with hydrothermal stability. J. Am. Chem. Soc. 2009, 131, 414-415. [CrossRef] [PubMed]

5. Kanezashi, M.; Yada, K.; Yoshioka, T.; Tsuru, T. Organic-inorganic hybrid silica membranes with controlled silica network size: Preparation and gas permeation characteristics. J. Membr. Sci. 2010, 348, 310-318. [CrossRef]

6. Tsuru, T.; Hino, T.; Yoshioka, T.; Asaeda, M. Permporometry characterization of microporous ceramic membrane. J. Membr. Sci. 2001, 186, 257-265. [CrossRef]

7. Tsuru, T.; Takata, Y.; Kondo, H.; Hirano, F.; Yoshioka, T.; Asaeda, M. Characterization of sol-gel derived membranes and zeolite membranes by nanopermporometry. Sep. Purif. Technol. 2003, 32, 23-27. [CrossRef] 
8. Chang, K.-S.; Yoshioka, T.; Kanezashi, M.; Tsuru, T.; Tung, K.-L. Molecular simulation of micro-structures and gas diffusion behavior of organic-inorganic hybrid amorphous silica membranes. J. Membr. Sci. 2011, 381, 90-101. [CrossRef]

9. Tsuru, T.; Shintani, H.; Yoshioka, T.; Asaeda, M. A bomodal catalytic membrane having a hydrogenpermselective silica layer on bimodal catalytic support: Preparation and application to the steam reforming of methane. Appl. Catal. Gen. 2006, 302, 78-85. [CrossRef]

10. Kanezashi, M.; Lin, Y.S. Gas permeation and diffusion characteristics of MFI-type zeolite membranes at high temperatures. J. Phys. Chem. C 2009, 113, 3767-3774. [CrossRef]

11. Kanezashi, M.; Lin, Y.S.; Suzuki, K.; O’Brien-Abraham, J.; O’Brien-Abraham, J. Gas permeation through DDR-type zeolite membranes at high temperatures. AIChE J. 2008, 54, 1478-1486. [CrossRef]

12. ten Hove, M.; Luiten-Olieman, M.W.; Huiskes, C.; Nijmeijer, A.; Winnubst, L. Influence of the intermediate layer on the hydrothermal stability of sol-gel derived hybrid silica membranes. J. Eur. Ceram. Soc. 2017, 37, 3435-3441. [CrossRef]

13. ten Hove, M.; Luiten-Olieman, M.W.; Huiskes, C.; Nijmeijer, A.; Winnubst, L. Hydrothermal stability of silica, hybrid silica and Zr-doped hybrid silica membranes. Sep. Purif. Technol. 2017, 189, 48-53. [CrossRef]

14. Agirre, I.; Arias, P.L.; Castricum, H.L.; Creatore, M.; Johan, E.; Paradis, G.G.; Ngamou, P.H.; van Veen, H.M.; Vente, J.F. Hybrid organosilica membranes and prpcess: Status and outlook. Sep. Purif. Technol. 2014, 121, 2-12. [CrossRef]

15. Nagasawa, H.; Matsuda, N.; Kanezashi, M.; Yoshioka, T.; Tsuru, T. Pervaporation and vapor permeation characteristics of BTESE-derived organosilica membranes and their long-term stability in a high-water-content IPA/water mixture. J. Membr. Sci. 2016, 498, 336-344. [CrossRef]

16. Yu, X.; Meng, L.; Niimi, T.; Nagasawa, H.; Kanezashi, M.; Yoshioka, T.; Tsuru, T. Network engineering of BTESE membrane for improved gas performance via a novel $\mathrm{pH}$-swing method. J. Membr. Sci. 2016, 511, 219-227. [CrossRef]

17. Khatib, S.J.; Oyama, S.T. Silica membranes for hydrogen separation prepared by chemical vapor deposition (CVD). Sep. Purif. Technol. 2013, 111, 20-42. [CrossRef]

(C) 2019 by the authors. Licensee MDPI, Basel, Switzerland. This article is an open access article distributed under the terms and conditions of the Creative Commons Attribution (CC BY) license (http://creativecommons.org/licenses/by/4.0/). 